\title{
Pulsed electric field processing preserves the antiproliferative activity of the milk fat globule membrane on colon carcinoma cells
}

\author{
S. Xu, ${ }^{*}$ M. Walkling-Ribeiro, ${ }^{*} \dagger$ M. W. Griffiths, ${ }^{*} \dagger$ and M. Corredig ${ }^{* 1}$ \\ *Department of Food Science, University of Guelph, Guelph, Ontario, Canada N1G 2W1 \\ †Canadian Research Institute for Food Safety (CRIFS), Guelph, Ontario, Canada N1G 2W1
}

\begin{abstract}
The present work evaluated the effect of processing on the antiproliferative activities of milk fat globule membrane (MFGM) extracts. The antiproliferative activity on human adenocarcinoma HT-29 cells of untreated MFGM extracts were compared with those extracted from pasteurized cream, thermally treated cream, or cream subjected to pulsed electrical field (PEF) processing. The PEF with a $37 \mathrm{kV} / \mathrm{cm}$ field strength applied for $1,705 \mu \mathrm{s}$ at 50 and $65^{\circ} \mathrm{C}$ was applied to untreated cream collected from a local dairy. Heating at 50 or $65^{\circ} \mathrm{C}$ for 3 min (the passage time in the PEF chamber) was also tested to evaluate the heating effect during PEF treatments. The MFGM extracted from pasteurized cream did not show an antiproliferative activity. On the other hand, isolates from PEF-treated cream showed activity similar to that of untreated samples. It was also shown that PEF induced interactions between $\beta$-lactoglobulin and MFGM proteins at $65^{\circ} \mathrm{C}$, whereas the phospholipid composition remained unaltered. This work demonstrates the potential of PEF not only a means to produce a microbiologically safe product, but also as a process preserving the biofunctionality of the MFGM.
\end{abstract}

Key words: milk fat globule membrane, pulsed electrical field, antiproliferative activity

\section{INTRODUCTION}

In native milk, fat is dispersed as fat globules, polydistributed in size and surrounded by a thin layer, called the milk fat globule membrane (MFGM). This membrane, consisting of phospholipids and proteins, protects fat globules from aggregation and chemical degradation. Because components derived from the MFGM have shown properties beneficial to health, interest has increased in recent years in the isolation of the MFGM as a functional ingredient. For example,

Received September 10, 2014.

Accepted October 29, 2014.

${ }^{1}$ Corresponding author: mcorredi@uoguelph.ca isolates from cream and buttermilk have antiproliferative activity against colon cancer cells both in vitro and in vivo (Snow et al., 2010; Zanabria et al., 2013), and immunomodulatory properties (Zanabria et al., 2014b).

Processing of milk, cream, or buttermilk may affect the structure and composition of the MFGM (Kim and Jimenez Flores, 1995; Michalski et al., 2002; Morin et al., 2007). During heating, protein denaturation and interactions occur between serum derived proteins and the MFGM (Kim and Jimenez-Flores, 1995). Nonthermal processing may reduce the extent of such interactions.

Pulsed electric field (PEF) has recently drawn a lot of attention as an emerging nonthermal processing technique (Sharma et al., 2014a). In brief, the exposure of liquid or semi-liquid food under a high voltage pulse of electrical fields for a very short duration can effectively inactivate microorganisms and some enzymes. The presence of ions contributes to the good electrical conductivity of the matrix, which is then adequate for PEF treatment (Zhang et al., 1995). The most recognized mechanisms for PEF-induced microbial inactivation are electrical disruption of cell membranes or cell membrane electroporation (Zimmermann, 1986; Castro et al., 1993; Sharma et al., 2014a).

The potential utilization of PEF in milk has been evaluated (Calderón-Miranda et al., 1999; Smith et al., 2002; Chugh et al., 2014; Sharma et al., 2014b). Most of the research has focused on quality and safety aspects, mainly on the efficiency of inactivation of bacteria and enzymes. It has been recently shown that PEF treatments of whole milk at 22 to $28 \mathrm{kV} \cdot \mathrm{cm}^{-1}$ for less than $100 \mu \mathrm{s}$ at $55^{\circ} \mathrm{C}$ causes reduction below the detection limit for Listeria innocua and Staphylococcus aureus (Sharma et al., 2014b). Researchers have also looked specifically to PEF treatment of cream (Picart et al., 2002) and found no significant differences with regard to microbial inactivation in comparison with whole milk. On the other hand, a different study (RodríguezGonzález et al., 2011) was suggested to increase the PEF intensity when treating cream instead of whole milk, to ensure comparable microbial safety. 
Pulsed electric field shows potential as a nonthermal technique that, when applied to liquid or semi-liquid food, can minimize the effect of processing on bioactive components (Mathys et al., 2013). It has been recently demonstrated that MFGM shows antiproliferative activity against human adenocarcinoma HT-29 cells (Zanabria et al., 2013), but the bioactivity is reduced after heating (Zanabria et al., 2014a). The present research focused on the effect of PEF processing of the cream on the bioactivity of the MFGM fraction prepared from it. It was hypothesized that PEF may preserve the structure and biological function of the MFGM. To test this hypothesis, the antiproliferative activity of MFGM isolates obtained from PEF-treated cream was tested and compared with that of MFGM obtained from buttermilk made from untreated cream.

\section{MATERIALS AND METHODS}

Fresh raw cream (about $40 \%$ fat) and pasteurized cream (about $40 \%$ fat, heated at $80^{\circ} \mathrm{C}$ for $16 \mathrm{~s}$ ) were obtained from Gay Lea Foods (Guelph, ON, Canada) immediately after separation. Cream samples were not homogenized. Immediately after collection, the cream was placed in an ice bucket. Further treatments were conducted in the laboratory.

\section{PEF Equipment and Treatment}

The PEF system includes a pump, oscilloscope for control and monitoring, prototype PEF chamber, pretreatment heating/cooling unit, posttreatment cooling unit, and temperature regulation system. The PEF generating system (PPS 30, University of Waterloo, Waterloo, ON, Canada) was custom built and assembled with an electrical field reactor prototype, which was engineered at the University of Guelph (Chugh et al., 2014). The system was connected to a 2-channel digital storage oscilloscope (TD 1012, Tektronix Inc., Beaverton, OR). The processing chamber consisted of 2 coaxially arranged electrodes with a $0.21-\mathrm{cm}$ electrode gap. The cylindrical electrodes, cooled or heated by an external jacket, were surrounded by a plastic coating made of an autoclavable insulated chemically resistant material. At the edge of the stainless steel electrodes were autoclavable gaskets to avoid leakage. The total volume of the reactor jacket was $790 \mathrm{~cm}^{3}$, with an inner electrode and outer electrode exposing 37.43 and 39.54 $\mathrm{cm}^{2}$ treatment surface area, respectively. The capacity of the processing chamber was $44 \mathrm{~cm}^{3}$, including a 24.93 $\mathrm{cm}^{3}$ volume allowing product exposure to electrical pulses when passing between the 2 electrodes.
The high-voltage pulse generating system contained 2 charging capacitors, with a capacitance of $0.31 \mu \mathrm{F}$, connected with a thyratron switch (TM-27, Tektronix Inc.). The device generated monopolar exponential decay pulses with a pulse width of $1.5 \mu$ s, which can be measured by a high voltage probe (P6015A, Tektronix Inc.).

At a flow rate of $25 \mathrm{~mL} / \mathrm{min}$, unprocessed cream was driven by a peristaltic pump (Masterflex pump drive 7524-40, Cole Parmer Instrument Co., Vernon Hills, IL) fitted with an extended pump head (Masterflex Easy Load II pump head 77201-62, Cole Parmer Instrument Co.). The cream was passed through peroxide-cured silicone tubing (Masterflex L/S 16, Cole Parmer Instrument Co.). The water circulates the reactor jacket connected to a water bath to control the temperature of the jacket circulation system (Masterflex L/S 35, Cole Parmer Instrument Co.). The temperature before and after treatment in the processing chamber was measured at its inlet and outlet point and recorded by a portable wireless data-logger (OM-SQ2020-2F8, Omega, Stamford, CT), connected to T-type thermocouples (TMTSS-040G-6, Omega). The temperature of circulating water at the entrance and exit of the chamber jacket was also measured, as well as that of the processed product following cooling in a refrigerated water bath (NESLAB RTE 7, Thermo Fisher Scientific Inc., Newlington, NH), in which the tubing was immersed. This cooling step caused a decrease in product temperature to approximately $10^{\circ} \mathrm{C}$.

The heat-assisted PEF processing of fresh raw cream was carried out using an electrical field strength of $37 \mathrm{kV} / \mathrm{cm}$ for a total treatment time of $1,705 \mu \mathrm{s}$. The maximum temperature in the reactor was either 50 or $65^{\circ} \mathrm{C}$, corresponding to energy densities of 148 and 193 $\mathrm{kJ} / \mathrm{L}$. Processed cream samples were kept cold in an ice bath.

Control treatments for PEF were carried out by heating the fresh raw cream in a water bath at 50 or $65^{\circ} \mathrm{C}$. The heating time in this case was longer $(3 \mathrm{~min})$ than the actual holding time in the PEF chamber (166 s). Samples were preheated in another water bath held at a temperature $10^{\circ} \mathrm{C}$ higher than the required temperature to ensure rapid increase in temperature, and then immediately transferred to the water bath setting at the required temperature $\left(50\right.$ or $\left.65^{\circ} \mathrm{C}\right)$ for $3 \mathrm{~min}$. The samples were heated in 50-mL centrifuge tubes (Fisher Scientific, Mississauga, ON, Canada) along with manual agitation to ensure rapid heating. After heating, cream samples were immediately cooled in an ice bath. All the treatments were repeated at least 3 times ( 3 batches of cream). 


\section{MFGM Isolation}

The MFGM isolates were obtained from the water phase (buttermilk) separated during a butter-making process. A bench-size churn was employed to obtain butter and buttermilk. Fresh raw cream or PEFtreated cream were kept refrigerated at $4^{\circ} \mathrm{C}$ overnight and churned at $10^{\circ} \mathrm{C}$ until apparent phase inversion occurred; this usually took between 15 and $30 \mathrm{~s}$, depending on the volume of cream processed. The butter grains were separated from the water phase (buttermilk) using a cheese cloth.

The MFGM was obtained from buttermilk as previously reported in the literature (Corredig and Dalgleish, 1997). Sodium citrate, $2 \%$ (wt/vol), was added to the buttermilk, which was then kept at $4^{\circ} \mathrm{C}$ overnight. Treated buttermilk was centrifuged at $70,000 \times g$ for $45 \mathrm{~min}$ at $15^{\circ} \mathrm{C}$ (Optima LE-80K, Beckman Coulter). After discarding the supernatant, the pellets were washed with MilliQ water and centrifuged again. The resulting pellets were resuspended in a small amount of MilliQ water and freeze-dried. Freeze-dried samples were stored at $-20^{\circ} \mathrm{C}$.

\section{Carcinoma Cell Growth}

Human adenocarcinoma HT-29 cells (CRIFS culture collection, Guelph, ON, Canada) were maintained in Dulbecco's modified Eagle medium (Invitrogen Canada Inc., Burlington, ON, Canada) in 25- or $75-\mathrm{cm}^{2}$ flasks (Corning Inc., Corning, NY) at $37^{\circ} \mathrm{C}$ with $5 \% \mathrm{CO}_{2}$ and sustaining humidity. Heat-inactivated fetal bovine serum (10\%; Invitrogen, Canada Inc.), 1\% (vol/ vol) penicillin-streptomycin (Invitrogen Canada Inc.), and $2 \mathrm{~m} M$ L-glutamine (Sigma-Aldrich Canada Ltd., Oakville, ON, Canada) were added to Dulbecco's modified Eagle medium. The medium was replaced with fresh prewarmed culture medium every $2 \mathrm{~d}$ until the HT-29 cells monolayer showed 80 to $90 \%$ confluency. Cells were reseeded weekly by applying a $0.25 \%$ trypsin solution containing $1 \mathrm{~m} M$ EDTA-4Na (Invitrogen Canada Inc.) for $5 \mathrm{~min}$.

Trypan blue $(0.4 \% \mathrm{vol} / \mathrm{vol})$ was used to stain and disperse the detached cell suspension, and cells were counted with a hemocytometer to determine the volume of cell suspension required for reseeding (approximately $5 \times 10^{4}$ cells $/ \mathrm{mL}$ ). The viable cells were distinguished from the stained cells (nonviable) and were maintained for 19 to 29 passages to ensure constant vitality.

Cell proliferation was tested using a cell proliferation ELISA BrdU (colorimetric assay) kit (Roche Applied Science, Quebec, Canada). The freeze-dried MFGM samples were dissolved with ultrapure water to give a final concentration of $2 \mathrm{mg} / \mathrm{mL}$ just before use and kept at $4^{\circ} \mathrm{C}$. The HT-29 cells were seeded at $2 \times 10^{3}$ cells per well in a clear 96-well microplate (Corning Inc.). After $24 \mathrm{~h}$, prewarmed medium mixed with reconstituted MFGM solution was exchanged to reach a final MFGM concentration of 400, 200, or $100 \mu \mathrm{g} /$ $\mathrm{mL}$. The $\mathrm{C}_{2}$-Ceramide, known to have anticarcinogenic properties (Sigma-Aldrich Canada Ltd.) was applied as a positive control. Some wells contained water instead of MFGM fractions and were used as negative control samples. Wells with no cells were also included as blanks.

All treatments and controls were run in triplicate. After $24 \mathrm{~h}$ incubation, the treatments were replaced with prewarmed fresh medium to reduce nonspecific binding and decrease background noise (Zanabria et al., 2013). Then, BrdU reagent $(10 \mu \mathrm{L} /$ well $)$ was added and incubated for $2 \mathrm{~h}$. After that, DNA was denatured by adding $200 \mu \mathrm{L} /$ well of EtOH-HCl FixDenat solution, and the mixture was incubated for 30 min before antibody binding solution (100 $\mu \mathrm{L} /$ well $)$, washing solution $(300 \mu \mathrm{L} /$ well $)$, and substrate solution $(100 \mu \mathrm{L} /$ well) were added as per the manufacturer's instructions (Roche Applied Science). Before adding antibody binding solution, a filtered $2 \%$ (wt/vol) BSA solution in PBS was applied $(200 \mu \mathrm{L} /$ well $)$ as blocking buffer. Washing steps were carried out 7 times to reduce the background noise. After adding $50 \mu \mathrm{L} /$ well of $1 M$ sulfuric acid as the stopping solution, the absorbance of each well was measured at $450 \mathrm{~nm}$ with a Multilabel Counter (Wallac 1420 Victor Perkin-Elmer Life Sciences, Peterborough, ON, Canada). The absorbance value was directly related to the extent of cell proliferation. All values were expressed relative to the negative control (medium only).

\section{Protein Determination: SDS-PAGE}

The protein composition in the MFGM fractions isolated from raw, pasteurized, thermally treated, or PEF-treated creams was determined by SDS-PAGE under reducing conditions. The experiments were performed using a Bio-Rad electrophoresis unit (Bio-Rad Power Pac HC, Mississauga, ON, Canada). Aliquots (5 mg) of freeze-dried MFGM samples were dissolved in the sample buffer (Corredig and Dalgleish, 1998). The samples were denatured in SDS buffer containing 2-mercaptoethanol and heated at $95^{\circ} \mathrm{C}$ for $10 \mathrm{~min}$. Mixtures were then centrifuged (Eppendorf centrifuge 5410D, Brinkmann Instrument Inc., Westbury, NY) at $2,000 \mathrm{rpm}$ for $3 \mathrm{~min}$, before loading the samples onto the gels. A solution of polypeptides with known molecular weights was also loaded as standard. The gels 
were stained with Coomassie blue and destained with $45 \%$ methanol and $10 \%$ acetic acid. The intensity of the protein bands was measured using a scanner (Bio-Rad Gel Doc EZ Imager) and evaluated with Image Lab Software (version 3.0, Bio-Rad).

\section{Phospholipids Determination: ${ }^{31} P$ Nuclear Magnetic Resonance Spectroscopy}

Approximately $50 \mathrm{mg}$ of each freeze-dried MFGM were placed in a $15-\mathrm{mL}$ centrifuge tube (Fisher Scientific, Mississauga, ON, Canada). One milliliter of 0.1 $M \mathrm{NaCl}$ and $4 \mathrm{~mL}$ of $\mathrm{CHCl}_{3} / \mathrm{CH}_{3} \mathrm{OH}$ (2:1 by vol) were added to dissolve the sample. After shaking vigorously for $1 \mathrm{~min}$, the mixed solution was centrifuged (Heraeus Multifuge X1R centrifuge, Thermo Fisher Scientific, Waltham, MA) at approximately $1,500 \times g$ for $15 \mathrm{~min}$ at room temperature to ensure phase separation. The lower organic phase was collected and transferred to another 15-mL centrifuge tube (Fisher Scientific, Mississauga, $\mathrm{ON}$, Canada), and $1 \mathrm{~mL}$ of $0.1 \mathrm{M} \mathrm{NaCl}$ and $4 \mathrm{~mL}$ of $\mathrm{CHCl}_{3} / \mathrm{CH}_{3} \mathrm{OH}$ (2:1 by vol) were added. The samples were then centrifuged under the same conditions described above, and the entire process was repeated 3 times in total. After the third centrifugation, the accumulated organic phase (approximately $12 \mathrm{~mL}$ in total) was transferred to a glass tube and evaporated in a nitrogen evaporator (Zanntek Analytical Evaporator, Glas Col, Terre Haute, IN) at room temperature. The purified, dried lipids of MFGM were stored at $-20^{\circ} \mathrm{C}$ for further analysis.

Various concentrations of 5 phospholipids [L- $\alpha-$ phosphatidylcholine and L- $\alpha$-phosphatidylethanolamine from egg, L- $\alpha$-phosphatidylserine from porcine brain, sphingomyelin from bovine milk (Avanti Polar Lipids, Alabaster, AL), and L- $\alpha$-phosphatidylinositol (SigmaAldrich Canada Ltd.) from soybean] were used as standards.

A ternary solvent with $\mathrm{CDCl}_{3} / \mathrm{CH}_{3} \mathrm{OH} / \mathrm{K}_{4}$ EDTA (100:40:20 by vol) was used to dissolve lipids from freeze-dried MFGM samples or the phospholipids standards. The $\mathrm{K}_{4}$ EDTA solution was prepared by dissolving $\mathrm{K}_{4}$ EDTA reagent (Sigma-Aldrich Canada Ltd.) in MilliQ water to reach a $0.2 M$ concentration. The glass vials with gently mixed sample solvent were stored overnight at room temperature to ensure clear phase separation. Precisely $600 \mu \mathrm{L}$ of the lower organic phase were collected and transferred into a 5-mm nuclear magnetic resonance tube (Sigma-Aldrich Canada Ltd.) with a Hamilton syringe (Hamilton Company, Reno, NV). Subsequently, $2 \mu \mathrm{L}$ of triethyl phosphate was added also using a Hamilton syringe as the internal reference.
A Bruker Avance 600-MHz instrument (Bruker, Billerica, MA) operating at $243 \mathrm{MHz}$ for ${ }^{31} \mathrm{P}$ was employed in this work. The key component of the spectrometer was a 5-mm probe, with deuterium field frequency stabilization and automatic field-homogeneity adjustment to maintain a stable temperature. Spectra was acquired at $10,000-\mathrm{Hz}$ sweep width, $50-\mu$ s pulse width, $30^{\circ}$ pulse angle, 10-s relaxation delay, 2-s acquisition time, and $6.5-\mu$ s prescan delay at $297^{\circ} \mathrm{K}$. Six hundred scans were done for the MFGM samples and 16 scans for the phospholipid standards. All measured chemical shift and line-widths were referenced to triethyl phosphate. The weights of different MFGM samples before lipid extraction were also considered.

\section{Statistical Analysis}

Three separate batches of cream were processed, and the data are presented as averages. Statistical analysis was carried out using R (version 2.15.1, R Foundation for Statistical Computing, Vienna, Austria) and Microsoft Excel 7.0 software. An ANOVA was carried out to analyze data from various experiments, and multiple comparisons of treatments means were analyzed by the Tukey (honestly significant difference) test. Differences between means at $P<0.05$ were considered significant.

\section{RESULTS AND DISCUSSION}

\section{Protein Composition}

Figure 1 shows the protein migration analyzed by SDS-PAGE under reducing conditions for MFGM isolates prepared from PEF-treated creams as well as their corresponding controls, untreated and pasteurized cream. The electrophoretic migration of MFGM extracts from $\mathrm{PEF}$-treated cream at $50^{\circ} \mathrm{C}$ was very similar to that obtained for untreated cream or cream heated at $50^{\circ} \mathrm{C}$. Similarly to the MFGM from fresh raw cream (Figure 1, lane 6), the $50^{\circ} \mathrm{C}$ treated sample (lane 2) showed only traces of the serum proteins and caseins. The major bands were assigned to xanthine oxidase (XO, $145 \mathrm{kDa})$, butyrophilin (BTN, $67 \mathrm{kDa})$, and glycoproteins PAS 6 and PAS 7 (50 and $47 \mathrm{kDa}$, respectively; Mather, 2000). The MFGM from pasteurized cream (Figure 1, lane 7), in addition to the MFGM proteins, showed a marked increase of serum-derived proteins in the samples, especially $\kappa$-casein and $\beta$-LG. The interactions between milk proteins and MFGM with heating have been reported, and the results were in full agreement with the literature (Kim and Jimenez Flores, 1995; Ye et al., 2004). Very little $\alpha$-LA was recovered in any of the isolates analyzed. On the other 


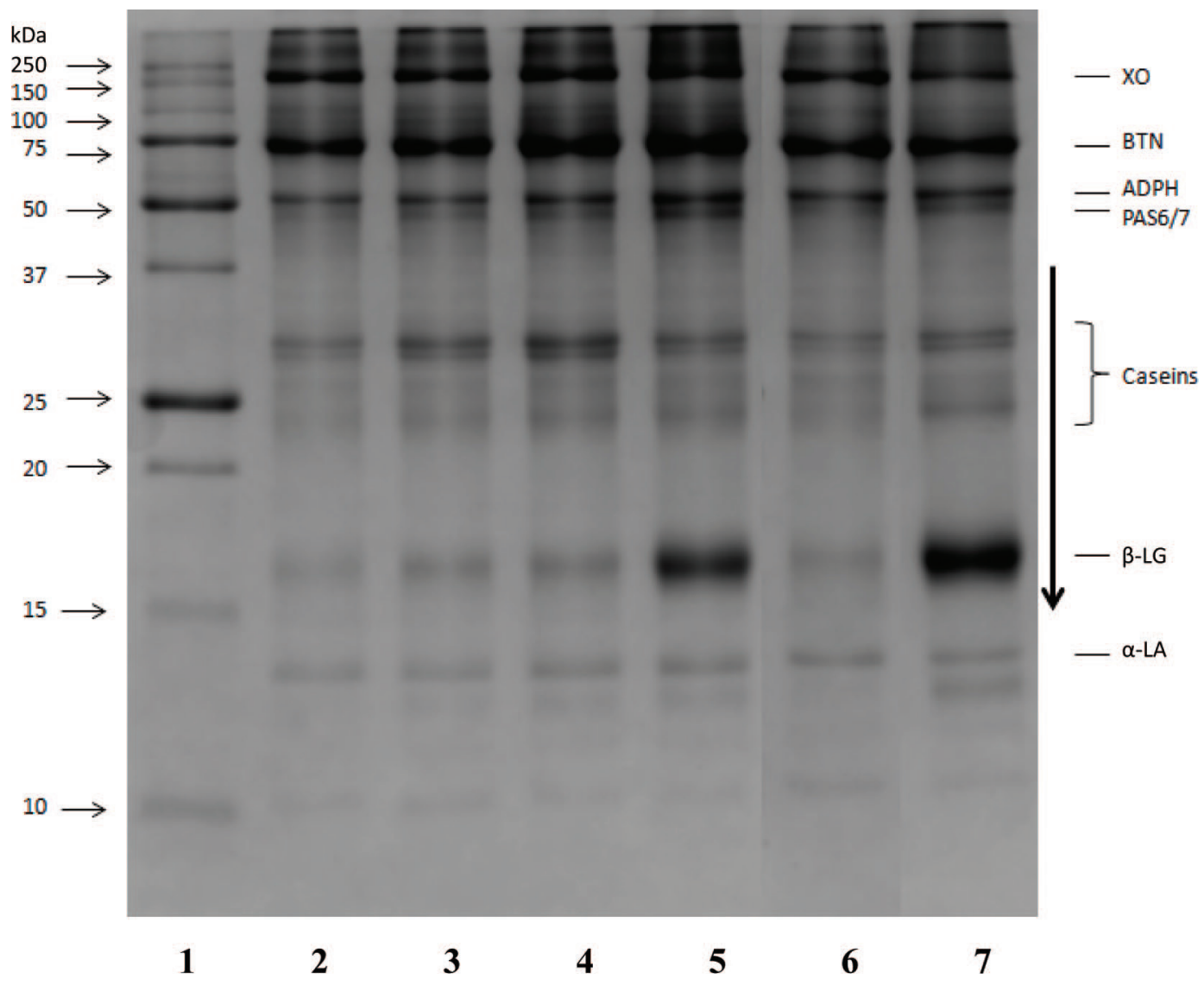

Figure 1. Sodium dodecyl sulfate-PAGE of milk fat globule membrane (MFGM) isolates from cream treated at $50^{\circ} \mathrm{C}$ for 3 min $($ lane 2 ), pulsed electrical field $(\mathrm{PEF})$ at $50^{\circ} \mathrm{C}$ (lane 3$), 65^{\circ} \mathrm{C}$ for $3 \mathrm{~min}$ (lane 4), $\mathrm{PEF}$ at $65^{\circ} \mathrm{C}$ (lane 5), unheated cream (lane 6), pasteurized cream (lane 7). Lane 1 molecular mass standard. XO = xanthine oxidase, BTN = butyrophilin, ADPH = adipophilin, PAS6/7 = glycoproteins PAS6 and PAS7. Arrow indicates the direction of migration. The gel is representative of 3 independent experiments.

hand, some differences could be noted in the samples treated at $65^{\circ} \mathrm{C}$ (Figure 1, lanes 4 and 5). In the PEF sample heated at $65^{\circ} \mathrm{C}$ (lane 5), the amount of caseins decreased and a significant $\beta-L G$ band appeared. This showed an effect of PEF on the interactions between $\beta$-LG and the MFGM.

Previous researchers (Hemar et al., 2011) showed that PEF $\left(45 \mathrm{kV} / \mathrm{cm}\right.$ field strength for $20 \mu \mathrm{s},<30^{\circ} \mathrm{C}$ ) treatment of milk causes a size reduction of the casein micelles as well as a reduction in viscosity of skim milk and milk concentrates. However, this effect was also noted after turning off the PEF device and was then attributed the shear stress applied to the milk during PEF treatment (Hemar et al., 2011). It is important to note that the thermal control in this study was not sheared, as heating was conducted in the water bath. However, as the interactions of $\beta$-LG with the MFGM proteins were not present at $50^{\circ} \mathrm{C}$ but at $65^{\circ} \mathrm{C}$, the effect of shear may be ruled out. Electroporation induced by $\mathrm{PEF}$ is ascribed to electric charge polarization (Zim- mermann et al., 1974). The combined action of moderate heat and PEF may have led to charge alterations causing structural changes leading to aggregation of $\beta$-LG (Bromley et al., 2005; Chen and Wu, 2006).

\section{Changes in Phospholipid Composition}

The phospholipids composition after PEF treatment was determined by ${ }^{31} \mathrm{P}$ nuclear magnetic resonance spectroscopy. The total peak area and the area of the major peaks were used to measure changes in phospholipids composition. Figure 2 represents the quantification of 3 indicators, the third peak of $\mathrm{L}-\mathrm{\alpha}-$ phosphatidylinositol, L- $\alpha$-phosphatidylcholine, and total phospholipids to provide an overall indication of the compositional change in phospholipids as a function of treatment. All samples were expressed as percentages by comparison with the fresh raw sample (100\%). No substantial changes were observed in the PEF-treated samples, but changes were observed in 


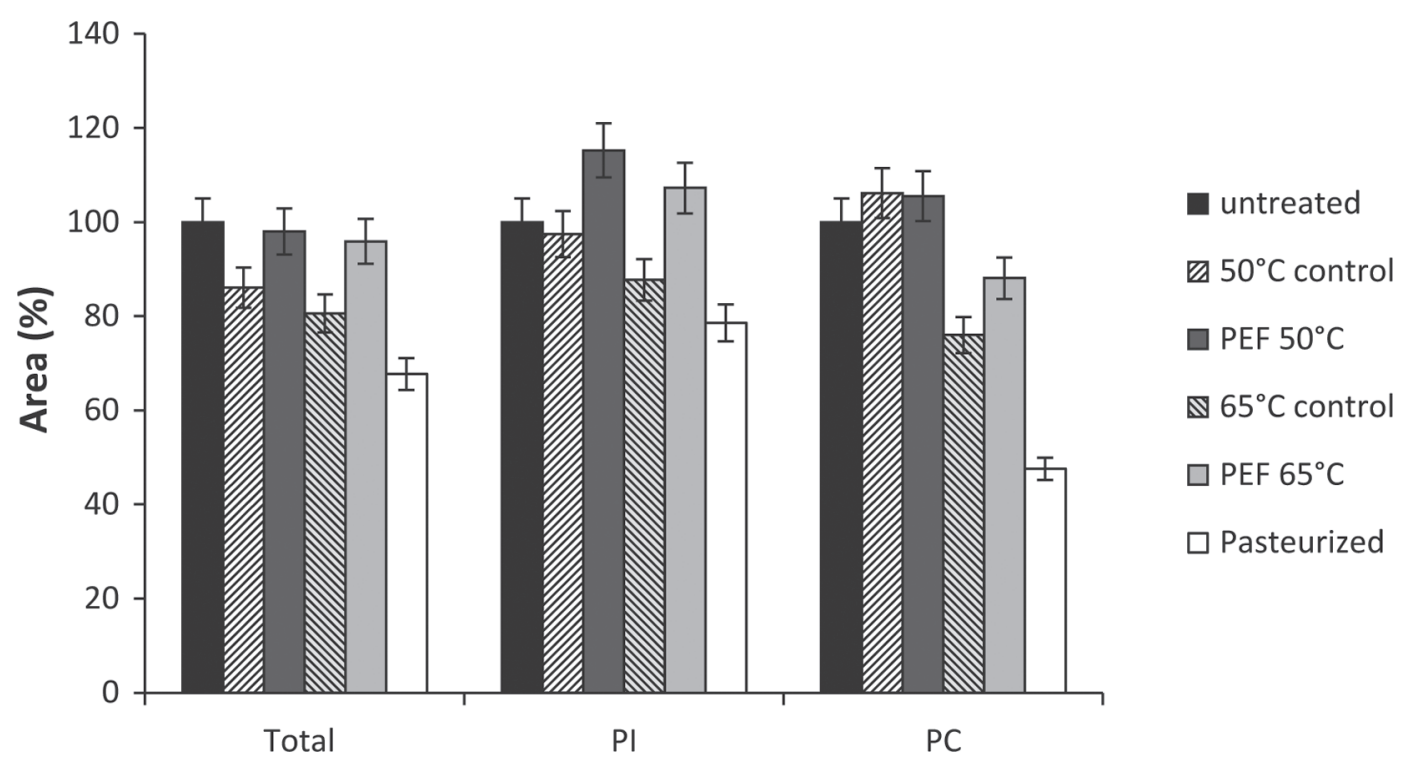

Figure 2. Total phospholipids, phosphatidyl inositol (PI), and phosphatidyl choline (PC) measured by ${ }^{31} \mathrm{P}$ nuclear magnetic resonance spectroscopy. Extracts prepared from untreated cream, pasteurized cream, pulsed electrical field (PEF) cream treated at 50 and $65^{\circ} \mathrm{C}$ and respective controls heated at 50 and $65^{\circ} \mathrm{C}$ for 3 min. Results are expressed as percentage of the total peak area for milk fat globule membrane (MFGM) from unheated cream. Average of 3 experiments, with bars representing standard deviations.

the control treated at $65^{\circ} \mathrm{C}$. That effect may be due to the heating time in the water bath, which was slightly longer than the actual time spent in the PEF chamber. Pasteurized creams showed the most significant loss of phospholipids. It was concluded that the PEF samples had a similar phospholipid composition to their corresponding control, and more importantly, were similar to the fresh raw cream.

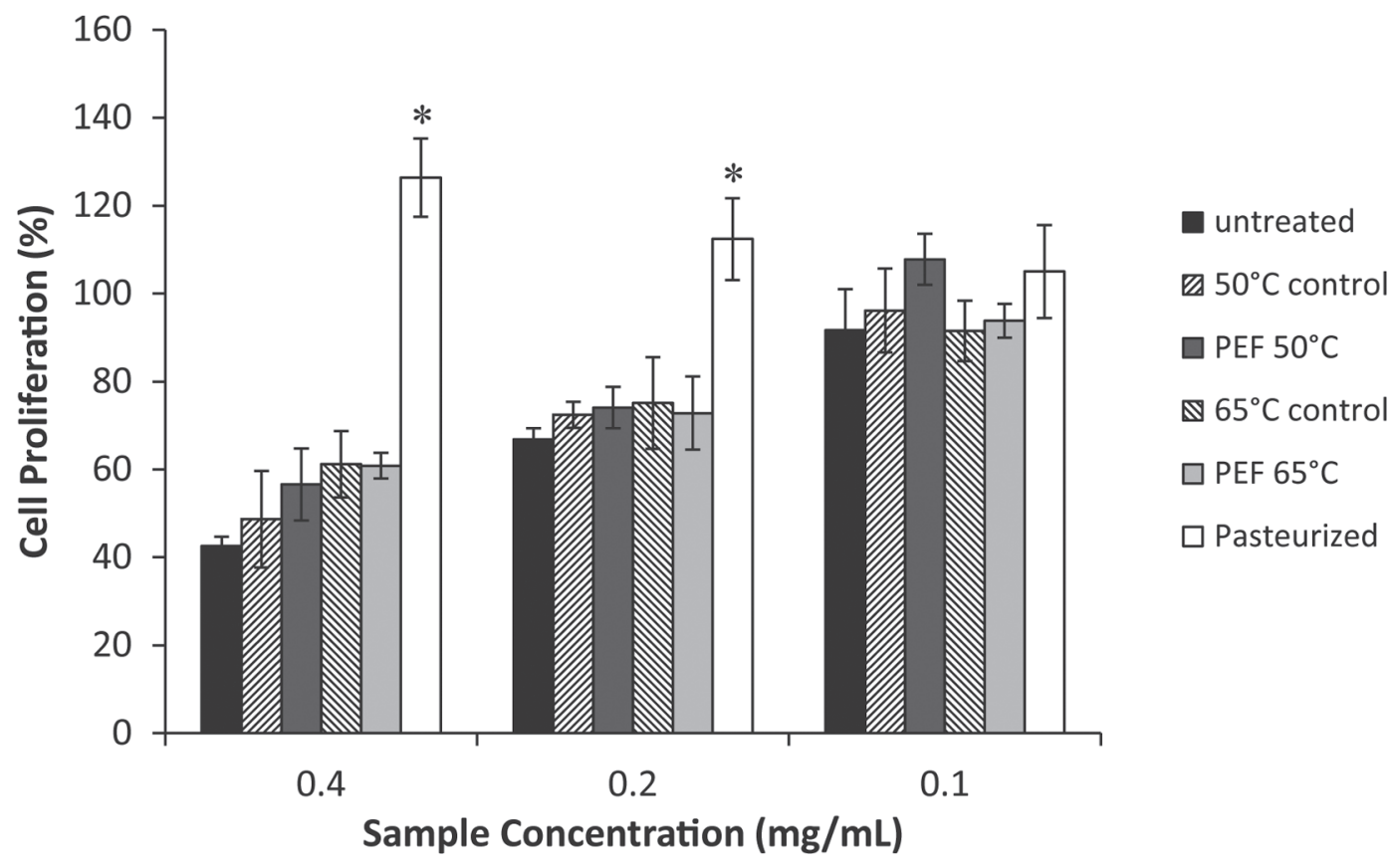

Figure 3. Effect of various milk fat globule membrane (MFGM) isolates on HT-29 cell proliferation. The MFGM were extracted from untreated cream, pasteurized cream, pulsed electrical field (PEF) cream treated at 50 and $65^{\circ} \mathrm{C}$ and respective controls heated at 50 and $65^{\circ} \mathrm{C}$ for 3 min. Cell proliferation was measured by the BrdU colorimetric method. All results represent 3 independent experiments, with bars representing standard deviations. ${ }^{*}$ Within a concentration, an asterisk indicates a significant difference at $P<0.05$. 


\section{Effect of PEF Treatment on the Antiproliferative Activity of the MFGM Isolates}

Figure 3 summarizes the effect of the MFGM isolates prepared from $\mathrm{PEF}$-treated cream on the proliferation of HT-29 colon cancer cells. The MFGM isolated from cream heated to $50^{\circ} \mathrm{C}$ did not show a decrease in bioactivity. The corresponding PEF sample treated at $50^{\circ} \mathrm{C}$ also showed a $43 \%$ reduction in cell proliferation, similar to the corresponding control and the MFGM extracted from unheated cream. The samples treated with PEF at $65^{\circ} \mathrm{C}$ showed a significant $39 \%$ reduction in cell proliferation. In this case, also, the efficacy was similar to that of the corresponding control sample (i.e., MFGM extracted from cream heated at $65^{\circ} \mathrm{C}$ ). These results indicate that the heat treatment and not the electrical field is responsible for the decrease in bioactivity.

Figure 3 also indicates that with a decrease in the concentration of MFGM extract, the anti-cell-proliferation efficacy also decreased. At the 2 lowest concentrations, the cell reduction remained approximately equivalent among all PEF-related samples and the fresh raw sample. At the $0.2 \mathrm{mg} / \mathrm{mL}$ sample concentration, a significant cell reduction is still observed for all the samples.

Figure 3 also indicated that the extract prepared from the industrially pasteurized cream did not prevent proliferation of HT-29 cells. These results are well in line with what was recently reported on the effect of heat on the antiproliferative activity of MFGM isolates (Zanabria et al., 2014a). Moreover, the growth of the cells increased at the highest concentrations, possibly due to the higher level of nutrients in these samples. These results may suggest an underestimation of the antiproliferative activities for the other MFGM extracts.

\section{CONCLUSIONS}

The MFGM extracted from untreated cream sampled from a bulk tank is active against proliferation of HT-29 colon cancer cells. The MFGM isolated from industrially pasteurized cream showed no antiproliferative activity against HT-29 colon cancer cells. Pulsed electrical field, in combination with mild heating (50 or $65^{\circ} \mathrm{C}$ ) maintained the bioactivity of the MFGM isolates to levels comparable with those of untreated MFGM. Pulsed electrical field induced aggregation of $\beta$-LG during treatment at $65^{\circ} \mathrm{C}$. Although the present results may suggest that the compositional changes occurring during processing, and more in particular, the amount of phospholipids in the MFGM fraction is critical to maintaining the bioactivity of the MFGM, more re- search is needed to understand which components are responsible for the observed antiproliferative effect.

\section{ACKNOWLEDGMENTS}

This work was a joint collaboration between the Ontario Dairy Council NSERC research program and the Dairy Farmers of Ontario research program. The authors thank Gay Lea Foods for their in-kind support of this project.

\section{REFERENCES}

Bromley, E. H. C., M. R. H. Krebs, and A. M. Donald. 2005. Aggregation across the length-scales in $\beta$-lactoglobulin. Faraday Discuss. 128:13-27.

Calderón-Miranda, M. L., G. V. Barbosa-Cánovas, and B. G. Swanson. 1999. Inactivation of Listeria innocua in skim milk by pulsed electric fields and nisin. Int. J. Food Microbiol. 51:19-30.

Castro, A. J., G. V. Barbosa-Cánovas, and B. G. Swanson. 1993. Microbial inactivation of foods by pulsed electric fields. J. Food Proc. Preserv. 17:47-73.

Chen, W., and W. H. Wu. 2006. Electric field-induced changes in membrane proteins charge movement currents. Burns 32:833-841.

Chugh, A., D. Khanal, M. Walkling-Ribeiro, M. Corredig, L. Duizer, and M. W. Griffiths. 2014. Change in color and volatile composition of skim milk processed with pulsed electric field and microfiltration treatments or heat pasteurization. Foods 3:250-268.

Corredig, M., and D. G. Dalgleish. 1997. Isolates from industrial buttermilk: Emulsifying properties of materials derived from the milk fat globule membrane. J. Agric. Food Chem. 45:4595-4600.

Corredig, M., and D. G. Dalgleish. 1998. Effect of heating of cream on the properties of milk fat globule membrane isolates. J. Agric. Food Chem. 46:2533-2540.

Hemar, Y., M. A. Augustin, L. J. Cheng, P. Sanguansri, P. Swiergon, and J. Wan. 2011. The effect of pulsed electric field processing on particle size and viscosity of milk and milk concentrates. Milchwissenschaft 66:126-128.

Kim, H. H. Y., and R. Jimenez-Flores. 1995. Heat-induced interactions between the proteins of milk fat globule membrane and skim milk. J. Dairy Sci. 78:24-35.

Mather, I. H. 2000. A review and proposed nomenclature for major proteins of the milk-fat globule membrane. J. Dairy Sci. 83:203247.

Mathys, A., S. Toepfl, C. Siemer, L. Favre, J. Benyacoub, and C. Hansen, inventors. 2013. Pulsed electric field treatment process and dairy product comprising bioactive molecules obtainable by the process. Nestle, assignee. WO Pat. No. 2013/007620.

Michalski, M.-C., F. Michel, D. Sainmont, and V. Briard. 2002. Apparent $\zeta$-potential as a tool to assess mechanical damages to the milk fat globule membrane. Coll. Surf. B Biointerfaces 23:23-30.

Morin, P., R. Jiménez-Flores, and Y. Pouliot. 2007. Effect of processing on the composition and microstructure of buttermilk and its milk fat globule membranes. Int. Dairy J. 17:1179-1187.

Picart, L., E. Dumay, and J. C. Cheftel. 2002. Inactivation of Listeria innocua in dairy fluids by pulsed electric fields: Influence of electric parameters and food composition. Innov. Food Sci. Emerg. Technol. 3:357-369.

Rodríguez-González, O., M. Walkling-Ribeiro, S. Jayaram, and M. W. Griffiths. 2011. Factors affecting the inactivation of the natural microbiota of milk processed by pulsed electric fields and crossflow microfiltration. J. Dairy Res. 78:270-278.

Sharma, P., P. Bremer, I. Oey, and D. W. Everett. 2014b. Bacterial inactivation in whole milk using pulsed electric field processing. Int. Dairy J. 35:49-56. 
Sharma, P., I. Oey, and D. W. Everett. 2014a. Effect of pulsed electric field processing on the functional properties of bovine milk. Trends Food Sci. Technol. 35:8-101.

Smith, K., G. S. Mittal, and M. W. Griffiths. 2002. Pasteurization of milk using pulsed electrical field and antimicrobials. J. Food Sci. 67:2304-2308.

Snow, D. R., R. Jimenez-Flores, R. E. Ward, J. Cambell, M. J. Young, I. Nemere, and K. J. Hintze. 2010. Dietary milk fat globule membrane reduces the incidence of aberrant crypt foci in Fischer-344 rats. J. Agric. Food Chem. 58:2157-2163.

Ye, A., H. Singh, M. W. Taylor, and S. Anema. 2004. Interactions of whey proteins with milk fat globule membrane proteins during heat treatment of whole milk. Lait 84:269-283.

Zanabria, R., A. M. Tellez, M. Griffiths, and M. Corredig. 2013. Milk fat globule membrane isolate induces apoptosis in HT-29 human colon cancer cells. Food Funct. 4:222-230.
Zanabria, R., A. M. Tellez, M. Griffiths, and M. Corredig. 2014a Antiproliferative properties of the milk fat globule membrane are affected by extensive heat treatment. Dairy Sci. Technol. 94:1-15.

Zanabria, R., A. M. Tellez, M. Griffiths, S. Sharif, and M. Corredig. 2014b. Modulation of immune function by milk fat globule membrane isolates. J. Dairy Sci. 97:2017-2026.

Zhang, Q. H., G. V. Barbosa-Cánovas, and B. G. Swanson. 1995. Engineering aspects of pulsed electric field pasteurization. J. Food Eng. 25:261-281.

Zimmermann, U. 1986. Electrical breakdown, electropermeabilization and electrofusion. Rev. Physiol. Biochem. Pharmacol. 105:176256.

Zimmermann, U., G. Pilwat, and F. Riemann. 1974. Dielectric breakdown in cell membranes. Biophys. J. 14:881-899. 